BANGLADESH J CHILD HEALTH 2011; VOL 35 (1): 6-10

\title{
Pregnancy Outcome of Mothers who Used Smokeless Tobacco for Five Years or More
}

\author{
MUJIBUL HOQUE ${ }^{1}$, MD. EKHLASUR RAHMAN ${ }^{2}$, PROBHAT RANJAN DEY ${ }^{3}$
}

\begin{abstract}
Background: Approximately 39\% women in Bangladesh use smokeless tobacco (ST). The incidence of adverse pregnancy outcomes like spontaneous abortion, stillbirth, preterm birth and delivery of low birth weight baby (LBW) are quite high in our country.

Objective: To determine the frequency of spontaneous abortion, stillbirth, delivery of preterm \& LBW baby of mothers who used ST for prolonged period.

Methodology: This retrospective cohort study was carried out in the Department of Paediatrics and Department of Obstetrics \& Gynecology, MAG Osmani Medical College Hospital, Sylhet, between July 2007 and June 2009. A total of 150 mothers using ST for 5 years or more \& their recently delivered newborn infants (mother-neonate pair) satisfying the selection criteria were enrolled as cases by purposive sampling. 150 suitably matched mother-neonate pairs were enrolled as controls. Detailed history of each mother about the outcome of recent and previous pregnancy/ pregnancies within the last 5 years was taken meticulously. Physical examination of the mother was done thoroughly. Each newborn was assessed for birth weight and gestational age.
\end{abstract}

Results: Baseline characteristics of cases and controls were comparable. Use of ST for $\geq 5$ years was significantly associated with spontaneous abortion $(P<0.01)$ and carried a risk of having spontaneous abortion 2.3 times more than that of non-ST users. It was also significantly associated with stillbirth $(P<0.01)$ and carried a risk of having stillbirth 2 times higher than that of non-ST users.

Use of ST for $\geq 5$ years was significantly associated with preterm delivery $(P<0.001)$ and carried a risk of having preterm delivery 3.1 times more than that of non-ST users. It was also significantly associated with delivery of $L B W$ baby $(P<0.001)$ and carried a risk of having delivery of LBW baby 4.1 times higher than that of non-ST users.

Conclusion: Frequency of spontaneous abortion, stillbirth, preterm delivery \& delivery of $L B W$ babies were much higher among mothers who used ST for about $7 \frac{1}{2}$ years. Women of child bearing age should be discouraged to use ST.

Key words: Smokeless tobacco, pregnancy outcome, spontaneous abortion, LBW baby.

\section{Introduction}

Tobacco, Nicotiana tabacam of solanacae family, was originally cultivated in North America, thousands of years ago and smoked by indigenous Americans at least 2000 years ago, spreaded throughout the world

1. Registrar, Department of Paediatrics, Sylhet M.A.G. Osmani Medical College Hospital, Sylhet.

2. Professor and Head, Department of Paediatrics, Dhaka Medical College, Dhaka.

3. Assistant Professor, Department of Paediatrics, Sylhet MAG Osmani Medical College, Sylhet

Correspondence: Dr. Mujibul Hoque after the arrival of the European settlers ${ }^{1}$. Tobacco is being used in various forms, predominantly as smoking and smokeless tobacco (ST). Paan chewing has existed as a habit in India and South East Asia for over 2000 years and it was a part of Mughal culture. Paan chewing became a widely prevalent form of smokeless tobacco use in India ${ }^{2}$. In Bangladesh commonly used smokeless tobaccos are: shada, jorda and gul. These are taken usually with betel quid, areca nut and lime. The use of smokeless tobacco mixed with areca nut is very popular in Bangladesh. 
Twenty two percent (22\%) of men and $39 \%$ of women use smokeless tobacco in chewable form in our country ${ }^{3}$.

Smoking is an established cause of adverse pregnancy outcome. Smoking is associated with higher rates of abortion, ectopic pregnancy, stillbirth, placenta previa, abruptio placentae, premature rupture of the membranes, preterm birth, intrauterine growth retardation and sudden infant death syndrome (SIDS) $)^{4,5}$.

Tobacco contains thousands of compounds that may have adverse effects on the human body. Nicotine is the major compounds of significance. Nicotine is metabolized to many different compounds, the most notable being cotinine. Nicotine and its active metabolite cotinine increases maternal blood pressure and heart rate. Fetal heart rate is also increased. There is concomitant reduction in the blood flow of uterine artery and umbilical artery ${ }^{6,7}$. Nicotine also impairs placental transfer of amino acids and affects fetal brain development which may cause fetal hypoxia and growth retardation 8.9 .

ST users are exposed to higher level of nicotine than smokers. The systemic absorption of nicotine per dose is greater with use of chewing tobacco (average 4.5 $\mathrm{mg}$ from average dose of $7.9 \mathrm{~g}$ chewed over 30 minutes) or snuff (average $3.6 \mathrm{mg}$ from an average $2.5 \mathrm{~g}$ moist snuff kept in mouth for 30 minutes) compared with that from smoking cigarettes (average $1 \mathrm{mg}$ per cigarette) ${ }^{10}$. Nicotine of ST may cause same adverse pregnancy outcome as smoking.

Tobacco is an important public health issue in Bangladesh, but a few studies had been carried out focusing adverse effects of tobacco on pregnancy outcome. One case control study carried out in a tertiary level hospital of Bangladesh showed that maternal antenatal use of ST about five times a day carries a risk of having IUGR infants 6.4 times than that of non-tobacco users ${ }^{11}$.

The present study was conducted to determine the frequency of spontaneous abortion, stillbirth, and delivery of preterm \& LBW baby of mothers who used ST for prolonged period.

\section{Patients and Methods}

This retrospective cohort study was done in Department of Paediatrics and Department of Gynecology and Obstetrics, Sylhet M.A.G. Osmani Medical College Hospital during the period between July, 2007 and June, 2009.

A total of 150 mothers taking ST for 5 years or more and had delivered recently a newborn infant (mother - newborn pair) were enrolled as cases and 150 suitably matched mother-newborn pairs were enrolled as controls. Cases were selected by purposive sampling. Inclusion criteria of the case were: (1) Mother using smokeless tobacco for 5 years or more and had delivered recently a newborn infant (2) Mother's age was between 20 and 40 years (3) Body mass Index (BMI) of the mother was more than 18.5 (4) Hemoglobin $(\mathrm{Hb} \%)$ level of mother was more than $10 \mathrm{gm} / \mathrm{dl}$.

Mothers having hypertension, pre-eclampsia, diabetes mellitus \& chronic renal disease, multiple gestations and smoker mothers were excluded from the study. Mothers who neither smoked nor took ST and had delivered recently a newborn infant were selected as controls. Matching was done with regards to age, BMI, socioeconomic status, paternal smoking and anemia.

Detailed history of each mother was taken. History included age, parity, socioeconomic status, smoking, passive smoking status, frequency and duration of taking ST.

History about the outcome of recent and previous pregnancy/ pregnancies within last 5 years was taken meticulously. Each mother was enquired about spontaneous abortion, stillbirth, preterm delivery \& also about term delivery. Mother was also enquired about the birth weight of her baby/ babies. If she could not mention the birth weight, she was asked about her perception about the size of the infant. Mother's perception about the size of the infant was validated by using 2 photographs - one of LBW baby and another one of normal weight baby. By seeing these, mother was invited to identify the size of her baby. Physical examination of the mother was done thoroughly which included weight, height, BMI, blood pressure, signs of systemic disease and signs of infection.

The newborn was assessed for birth weight, occipitofrontal circumference (OFC), supine length, and for signs of congenital infection. Gestational age of the neonate was determined by Last Regular Menstrual Period (LRMP) method and also by New Ballard Scoring System (NBS). In case of any discrepancy of more than two weeks, the latter was accepted.

Data were processed and analyzed using computer software (Microsoft Excel and SPSS-11). Ethical issues were addressed duly.

\section{Results}

Baseline characteristics regarding age, BMI, socioeconomic status, husband's smoking and $\mathrm{Hb}$ status of cases and controls were almost similar (Table - I). 
Table-I

Maternal baseline characteristics. $(N=150)$

\begin{tabular}{|c|c|c|c|}
\hline Characteristics & Cases & Controls & P-value \\
\hline 1. Total number & 150 & 150 & \\
\hline Age in years (Mean \pm SD) & $28.43 \pm 3.84$ & $27.79 \pm 4.10$ & $>0.05$ \\
\hline 3. $\mathrm{BMI}($ Mean $\pm \mathrm{SD})$ & $21.46 \pm 2.02$ & $21.32 \pm 1.88$ & $>0.10$ \\
\hline \multicolumn{4}{|l|}{ 4. Socio-economic status } \\
\hline Poor & $109(72.7 \%)$ & $104(69.3 \%)$ & \\
\hline Middle class & $41(27.3 \%)$ & $46(30.7 \%)$ & $>.05>.05$ \\
\hline Husband's smoking & $150(100 \%)$ & $150(100 \%)$ & \\
\hline 6. $\mathrm{Hb}$ status in $\mathrm{gm} / \mathrm{dl}($ Mean $\pm \mathrm{SD})$ & $10.96 \pm 0.61$ & $10.86 \pm 0.59$ & $>.05$ \\
\hline
\end{tabular}

Majority of mothers used shada (64\%) which was followed by jorda (25\%), mixed shada \& jorda (8\%) and gul (3\%) (Figure -l). Majority of mothers (57.3\%) used ST for an average of 7.7 ( \pm 2.9 ) years (Table $-I I)$. Frequency of spontaneous abortion among ST users

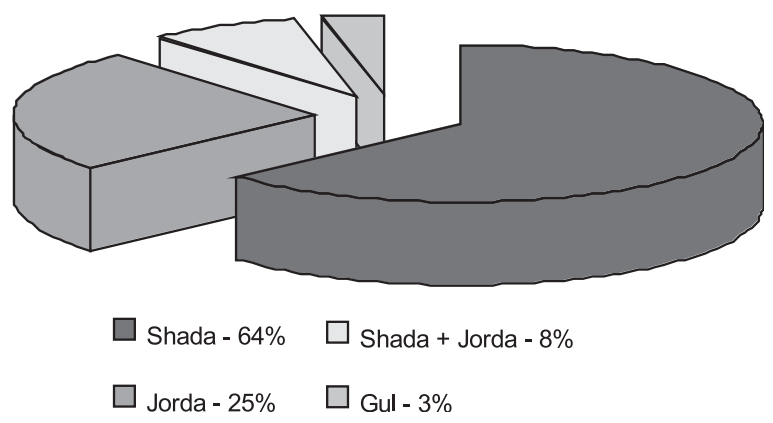

Fig.-1: Types of Smokeless Tobacco used by mothers.

Table-II

Duration of using Smokeless Tobacco by mothers.

\begin{tabular}{lcc}
\hline Duration in years & $\begin{array}{c}\text { No. of } \\
\text { mothers }(\%)\end{array}$ & $\begin{array}{c}\text { Mean duration } \\
( \pm \text { SD })\end{array}$ \\
\hline $5-7$ years & $86(57.3 \%)$ & $7.7( \pm 2.9)$ \\
$8-10$ years & $30(20.0 \%)$ & \\
$>10$ years & $34(22.7 \%)$ & \\
\hline
\end{tabular}

Table-III

Frequency of spontaneous abortion in women who used Smokeless Tobacco (ST) for $\geq 5$ years.

\begin{tabular}{lccc}
\hline & Yes & No & Total \\
\hline ST users & 47 & 103 & 150 \\
Non-ST users & 25 & 125 & 150 \\
\hline
\end{tabular}

$\chi^{2}$ value $=8.84$, P-value $=<0.01$, Odd ratio $=2.3$ was $31.33 \%$ and among non-ST users was $16.67 \%$. Use of ST for prolonged period is significantly associated with spontaneous abortion $(P<0.01)$ and carries a risk of having spontaneous abortion 2.3 times more than that of non-ST users (odds ratio 2.3) (Table -III). Frequency of stillbirth among ST users was 32\% and among non-ST users was $18.67 \%$. Use of ST for prolonged period is significantly associated with stillbirth $(P<0.01)$ and carries a risk of having stillbirth 2 times more than that of non-ST users (Odds ratio 2) (Table-IV). Frequency of preterm delivery among ST users was $44 \%$ and among non-ST users was $20 \%$. Use of ST for prolonged period is significantly associated with preterm delivery $(P<0.001)$ and carries a risk of having preterm delivery 3.1 times more than that of non-ST users (Table $-\mathrm{V}$ ). Frequency of LBW baby among ST users was $68.67 \%$ and among non-ST users was $34.67 \%$. Use of ST for prolonged period is significantly associated with delivery of LBW baby $(P<0.001)$ and carries a risk of having delivery of LBW baby 4.1 times more than that of non-ST users (Table-VI).

\section{Table-IV}

Frequency of stillbirth in women who used Smokeless Tobacco (ST) for $\geq 5$ years.

\begin{tabular}{lccc}
\hline & Yes & No & Total \\
\hline ST users & 48 & 102 & 150 \\
Non-ST users & 28 & 122 & 150 \\
\hline$\chi^{2}$ value $=7.04$, & P- value $=<0.01$, Odd ratio $=2$
\end{tabular}


Table-V

Frequency of preterm delivery in women who used Smokeless Tobacco (ST) for $\geq 5$ years.

\begin{tabular}{lccc}
\hline & Yes & No & Total \\
\hline ST users & 66 & 84 & 150 \\
Non-ST users & 30 & 120 & 150 \\
\hline
\end{tabular}

$\chi^{2}$ value $=19.86$, P- value $=<0.001$, Odds ratio $=3.1$

Table-VI

Frequency of delivery of $L B W$ baby in women who used Smokeless Tobacco (ST) for $\geq 5$ years.

\begin{tabular}{lccc}
\hline & Yes & No & Total \\
\hline ST users & 103 & 47 & 150 \\
Non-ST users & 52 & 98 & 150 \\
\hline
\end{tabular}

$\chi^{2}$ value $=34.72, \mathrm{P}$ - value $=<0.001$, Odds ratio $=4.1$

\section{Discussion}

Maternal tobacco exposure has a wide variety of adverse effects on pregnancy outcome. About $39 \%$ of women of our country use ST in chewable form ${ }^{3}$. In Bangladesh, use of ST with Paan, especially by women, is a socially and culturally accepted health damaging behavior. The present study found that about two-thirds of mothers used Shada, one-fourth used Jorda, a few percentages used both Shada \& Jorda and a fewer percentages used Gul. Two case control studies conducted locally found almost similar mode of ST ingestion by mothers ${ }^{11,12}$, but they found that maximum mothers used Jorda and no one used more than one type of ST. These differences may be due to their small sample sizes. Shada is relatively cheap and easily available. So it is expected that maximum women use Shada. Mixed use of Shada \& Jorda may be due to economical constraint. The poor women took Shada instead of Jorda as they could not meet the expense of Jorda always.

When women become addicted to ST products, they continue this habit years after years. Mothers included in the current study used ST on an average for 7.6 years.

Tobacco smoking is often considered as a risk factor for spontaneous abortion. Many studies reported the association between maternal smoking and increased risk of spontaneous abortion. The current study found that the risk of spontaneous abortion among the mothers who used ST for prolonged period was 2.3 times higher than non-ST users and there was significant association between ST use for prolonged period and spontaneous abortion $(p<0.01)$. A hospital based retrospective cohort study found almost similar association between maternal cigarette smoking and spontaneous abortion (odd ratio 3.3 and $p<0.05)^{13}$.

Maternal cigarette smoking has been causally associated with an increased risk of stillbirth. The present study found that the risk of stillbirth among the ST user mothers is 2 times more than non-ST users which indicates significant association between maternal ST use for prolonged period and stillbirth $(p<0.01)$. A prospective cohort study in Mumbai, India found the risk for stillbirth in ST users was $2.6^{14}$. Another study in India showed that the stillbirth rate for women who chewed tobacco, was 50/1000 total births, compared to $17.1 / 1000$ for those who did not ${ }^{15}$. These results support the result of the present study.

It is now established that tobacco smoking during pregnancy shortens the gestational period and increases the number of preterm deliveries. The current study found that the risk of preterm delivery among ST user mothers is 3.1 times higher than non-ST users. This study found highly significant association between ST use for prolonged period and preterm delivery with a $p$-value $<0.001$. The prospective cohort study in India found almost similar result ${ }^{16}$. A study in Bangladesh found that maternal ST use in pregnancy was significantly associated with preterm delivery and carries a risk of having preterm babies 4.6 times than non-ST users ${ }^{12}$. These findings are in conformity with the result of the current study.

Smoking is responsible for $20-30 \%$ of all LBW infants ${ }^{5}$. ST use is also associated with delivery of LBW babies in some reports. The present study found that the risk of delivery of LBW baby among the ST user mothers was 4.1 times higher than non-ST users group. The association between use of ST for prolonged period and delivery of LBW baby is highly significant $(p<0.001)$. Almost similar result was found in a prospective cohort study carried out in Mumbai, India ${ }^{16}$. Another study in India found that maternal Mishri use was associated with 3.2 times more risk of having a LBW baby ${ }^{17}$. The results of these two studies support the result of the current study. 


\section{Conclusion}

Frequency of spontaneous abortion, stillbirth, preterm delivery \& delivery of LBW babies were much higher among mothers who used ST for about $7 \frac{1}{2}$ years. Women of child bearing age should be discouraged to use ST.

\section{References}

1. Ravi S, Laurence S, Alen MF. Trends in Tobacco Use. Med Clin N Am 2004, 88(6):1392.

2. Reddy KS, Gupta PC. Report on Tobacco Control in India, New Delhi: Ministry of Health and Welfare, Government of India; 2004.

3. World Health Organization. Impact of Tobaccorelated Illness in Bangladesh. New Delhi; 2007.

4. Women and smoking: A Report of Surgeon General. Executive summary. MMWR Recomm Rep 2002; 51: I-iv, 1-13.

5. Andres RL, Day MC. Perinatal Complications Associated with Maternal Tobacco Use. Semin Neonatol 2000; 5 : 231-41.

6. Muller JS, Antunes M, Behle I, Teixeira L, Zielinsky P. Acute Effects of Maternal Smoking on Fetal-Placental-Maternal System Hemodynamics. Arq Bras Cardiol 2002; 78: 152155.

7. Lambers D, Clark K. The Maternal and Fetal Physiologic Effects of Nicotine. Semin Perinatol 1996; 20: 115-126.

8. Pastrakuljic A, Derewlany LO, Koren G. Maternal Cocaine Use and Cigarette Smoking in Pregnancy in Relation to Amino Acid Transport and Fetal Growth. Placenta 1999; 20: 499-512.

9. Slotkin TA. Fetal Nicotine or Cocaine Exposure: Which One is Worse? The Journal of
Pharmacology and Experimental Therapeutics 1998;285: 931-945.

10. Benowitz NL. Pharmacology of Smokeless Tobacco Use: Nicotine Addiction and Nicotinerelated Health Consequences. Nicotine Effect and Addiction. In National Cancer Institute, ST or Health: An International Perspective, Washington: US Department on Health and Human Services. Public Health Service: 1992; 93: 219-227.

11. Rahman ME, Khan IH, Parveen R. Role of Maternal Tobacco Use in The Development of IUGR Infants. Sylhet Med J 2007; 30: 16-22.

12. Hossain MA, Rahman ME. Role of Maternal Smokeless Tobacco Ingestion During Pregnancy in Delivery of Preterm Babies. Thesis, Shahjalal University of Sciences and Technology, 2008.

13. Rojas VD, Pardo JR, Arbiza PA, Molina PO. Spontaneous Abortion in a Hospital Population: Are Tobacco and Coffee Intake Risk Factors? Eur J Epidemiol 1994; 10:665-668.

14. Gupta PC, Sreevidya S. Smokeless Tobacco Use \& Risk of Stillbirth: A Cohort Study in Mumbai, India. Epidemiology 2006; 17(1): 47-51.

15. Krishna K. Tobacco Chewing in Pregnancy. $\mathrm{Br} \mathrm{J}$ Obstet Gynecol 1978; 85(10): 726-728.

16. Gupta PC, Sreevidya S. Smokeless Tobacco Use, Birth Weight \& Gestational Age: A Population Based Prospective Cohort Study of 1217 Women in Mumbai, India. BMJ 2004; 328: 1538-1542.

17. Krishnomurthy S, Joshi S. Gender Differences and Low Birth Weight with Maternal Smokeless Tobacco Use in Pregnancy. J Trop Pediatr. 1993; 39: 253-254. 